\title{
Antiestrogenic Compounds and Breast Cancer
}

\author{
Muhammad Asim¹, Noman Ali', Raheel Asghar', Awais Amin², \\ Muhammad Saif Ur Rahman ${ }^{3 *}$ \\ ${ }^{1}$ Department of Bioinformatics \& Biotechnology, Government College University Faisalabad, \\ Faisalabad, Pakistan \\ ${ }^{2}$ Department of Biomedical Engineering, College of Biomedical Engineering and Instrument Science, \\ Zhejiang University, Hangzhou, China \\ ${ }^{3}$ Clinical Research Center, The Second Affiliated Hospital, Zhejiang University School of Medicine, \\ Hangzhou, China

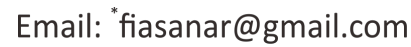

Received 29 February 2016; accepted 14 March 2016; published 18 March 2016

Copyright (C) 2016 by authors and OALib.

This work is licensed under the Creative Commons Attribution International License (CC BY).

http://creativecommons.org/licenses/by/4.0/

(c) (i) Open Access

\begin{abstract}
Breast cancer is the main threat around the world. Estrogen and estrogen receptors (ER) assume a noteworthy part in breast disease movement and advancement. Breast cancer is the most pervasive disease in women, every year more than 200,000 new cases analyzed. Estrogen receptors are expressed in $\mathbf{7 0 \%}$ of all the breast cancer cases, so it is an important target for the treatment of breast cancer. Anti-estrogen compounds are of significant importance since it can be used as a therapy for breast cancer. In this review we have summarized the most important anti-estrogen compounds being used for the treatment of the breast cancer and their related molecular pathways with the hope that this will enhance our understanding to these compounds.
\end{abstract}

\section{Keywords}

Breast Cancer, Anti-Estrogen Compounds, Bcl-2, GRP78, Caspase 8

Subject Areas: Oncology, Women's Health

\section{Introduction}

One out of each eight American women will create intrusive breast cancer through the span of her lifetime. An expected 230,000 new instances of breast disease are analyzed every year in the United States [1]. Of these cases, $70 \%$ will express estrogen receptor-alpha (ER- $\alpha$ ). ER- $\alpha$-targeted treatments incorporate the specific ER

${ }^{*}$ Corresponding author. 
modulator tamoxifen (TAM), the particular ER down regulator Faslodex (fulvestrant, ICI), or aromatase inhibitors that piece the change of androgens to estrogens. Indeed, even with the achievement of these medications, some tumors neglect to react (all over again resistance) or obtain resistance overtime [2] [3].

Breast tumor cells can obtain imperviousness to antiestrogens through changes in sub-atomic flagging that influence cell multiplication and passing. B-cell lymphoma 2 quality clan encodes focal administrative proteins with both antiapoptotic (B-cell lymphoma 2, BCLW, BCL-xL, MCL1, and A1) and pro-apoptotic capacities (BAX, BAK, and BH3-just proteins) [4]. BH3 communicates with the anti-apoptotic $\mathrm{BCL}_{2}$ proteins to advance apoptosis by actuating BAX and/or BAK, which prompts downstream cytochrome c discharge [5]. $\mathrm{BCL}_{2}$ additionally interfaces with beclin-1 (BECN1), a basic controller of autophagy that encourages auto-phagosome generation [6]. Before systemic treatment, $\mathrm{BCL}_{2}$ overexpression regularly connects with $\mathrm{ER}-\alpha$ and is generally a good prognostic marker [7]. Then again, $\mathrm{BCL}_{2}$ levels diminish in tumors that react to 3 months of tamoxifen treatment, though $\mathrm{BCL}_{2}$ expression is high in tumors that remain 3 months after tamoxifen [8] [9]. Along these lines, focusing on the antiapoptotic BCL2 relatives may be a valuable methodology to overcome antiestrogen resistance in some breast growths.

Most ER+ breast tumors that at first reacted to antiestrogen treatment still hold the ER upon tumor reoccurrence and $<25 \%$ of tumors lose ER expression after creating TAM resistance, proposing that injury of ER is not the main determinate of antiestrogen struggle [3] [10]. Other flagging pathways, for example, PI3K/Akt, IGF and EGF flagging, were embroiled in antiestrogen resistance. PI3K/Akt flagging was beforehand resolved to enact ER through direct phosphorylation of ER (Ser167) by Akt and avoid TAM-intervened apoptosis in breast tumor cells. Likewise, EGF and IGF initiation of MAPK flagging was appeared to phosphorylate ER; p90rsk phosphorylation of ER (Ser167), ERK1/2 phosphorylation of ER (Ser118) or through a MAPK-free pathway that may prompt ER enactment and antiestrogen resistance. Because of the redundancies in these atomic flagging pathways, effectively focusing on Akt or MAPK motioning to repress or restore antiestrogen affectability in the center has delivered to some degree baffling results [11] [12].

\section{Estrogen and Breast Cancer}

Estrogen is unique of the real hazard component of breast tumor movement and advancement. More than, $85 \%$ of the mammary tumors in women started from the luminal mammary epithelial cells. Adenocarcinogenesis are arranged by development prerequisites for multiplication has been either hormone ward or hormone free tumors [13]. Different investigations of breast disease have answered to an expanded danger connected with lifted blood levels of endogenous estrogen. The impact of serum estrogen focus is connected with the menstrual cycle in premenopausal women and steadier fixation in postmenopausal women [13] [14]. In creature test, estrogen is lead to improvement of mammary tumors and the systems of estrogen are added to every period of the adenocarcinogenesis procedure of ignition, advancement and movement [14] [15] (Figure 1).

\section{Signs and Symptoms}

Formation of lump which feels different from rest of the breast tissues is one of noticeable symptom of breast cancer [16] Other than lump formation, breast becoming large or lower, a nipple changes shape or position or become inverted. Rashes around the nipple or constant pain in armpit or breast part. Inflammatory breast cancer symptoms include inflammation, swelling, warmth and redness of breast. Weight loss and fever is also symptoms of breast cancer [17].

\section{Risk Factors}

With the increased in age breast cancer risk increases. A woman who is 60 years old 100 times more risk of breast than 20 years old. Breast cancer risk in male is lower than women. Nearly $99 \%$ breast cancer diagnosed in females in developed countries [18]. The overall prognosis is less worse in female than males. Alcohol beverages produce group 1 carcinogen which cause breast cancer [19], such as smoking causes breast cancer. If a woman consumes more alcohol more chances of breast cancer. Vitamin D deficiency may cause breast cancer in later stage [16].

\section{Breast Cancer Pathogenesis}

It is a malignant tumor which starts in breast cells. Just like other cancer there are many risk factors for breast 


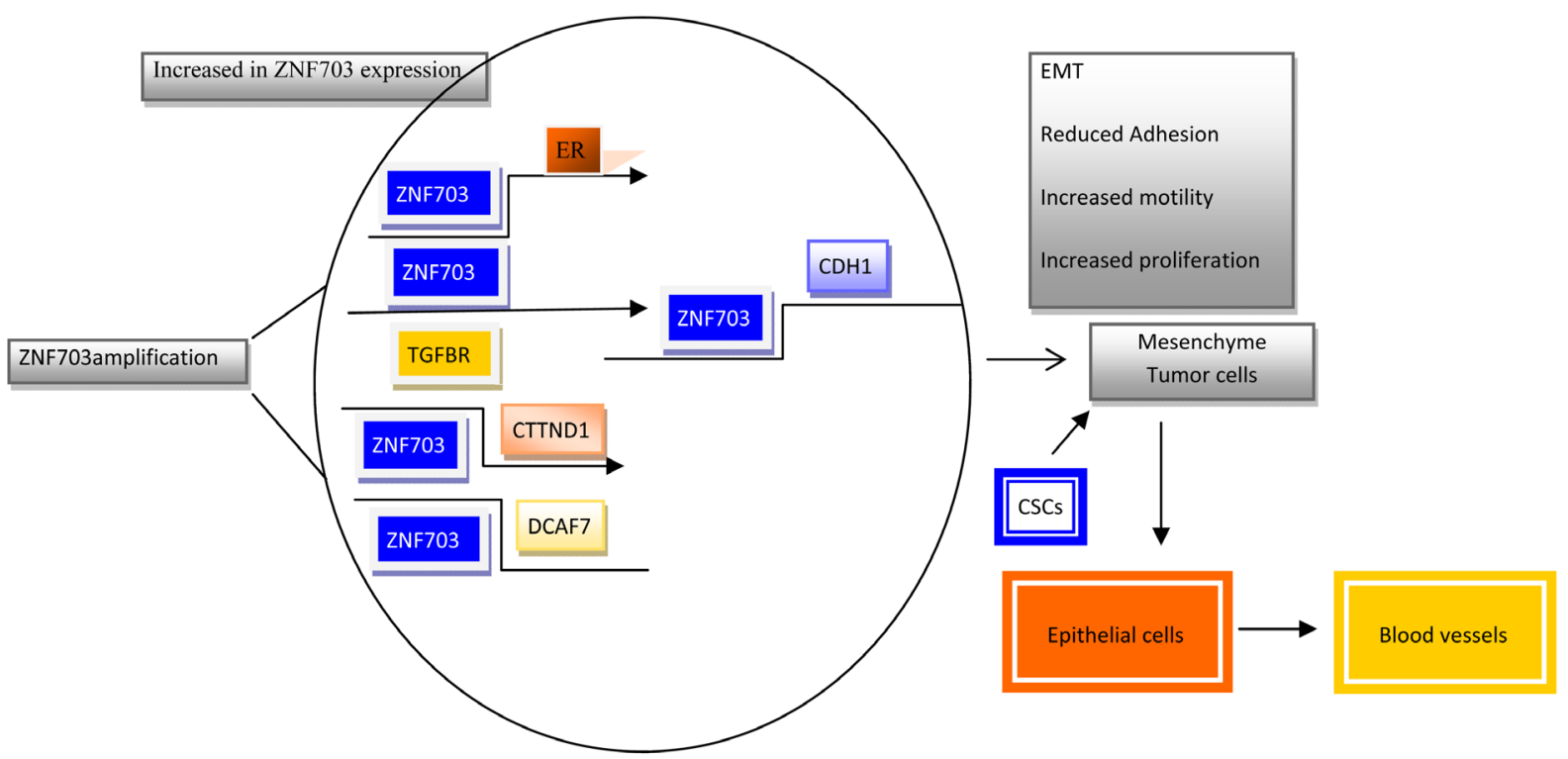

Figure 1. Shows that ZNF703 amplification increased ZNF703 expression which causes Mesenchyme Tumor in CSCs these tumor cells than transfer to blood vessels through epithelial cells. Increased ZNF703 expression cause reduced adhesion, EMT, Increased motility, increased proliferation.

cancer. DNA damage and genetic mutation can cause breast cancer. BRCA1, BRCA2 and P53 mutation can cause breast cancer. Increased risk for those which have family history of ovarian or breast cancer. The immune system normally seeks out cancer cells and cells with damaged DNA and destroys them. Breast cancer may be a result of failure of such an effective immune defence and surveillance. Disturbance in signaling system growth cells and other mediators may leads to breast cancer [20].

\section{Diagnosis}

Through biopsy or microscopy sample analysis easily diagnose many types of breast cancer. There are some breast cancers that need specialized lab exam. Most commonly screening methods include physicals examination by healthcare provide or by mammography can offer for lump cancer or some other lesions [21]. When these examinations are inconclusive than remove a sample of the fluid in the lump for microscopic analysis for diagnosis. If we find fluid clear than lump is highly unlike to cancerous, For good diagnosis physical examination also done mammography for good degree of accuracy, core biopsy in which a section of breast lump is removed or an excisional biopsy in which whole lump is removed. More over ultrasound and MRI is done for good diagnosis [22].

\section{Obstructing of Estrogen Receptors (Tamoxifen and Raloxifene)}

Tamoxifen are antiestrogen the coupling of estrogen-to-estrogen receptors. The FDA has affirmed Tamoxifen in 1977 for the cure of women with cutting edge breast growth [23]. The compound was directed to patients as trans-tamoxifen in light of the fact that this isomer has more fondness for estrogen receptors unlike cisisomer [24] Medications, for example, tamoxifen are all the more appropriately alluded to as specific estrogen-receptor modulators (SERM) as a result of their different exercises. It has estrogen-opponent action in breast tissue representing its capacity to restrain tumor development [25] (Figure 2). Tamoxifen is retained promptly after oral organization and the typical measurement is $20 \mathrm{mg}$ for every day and the serum partial-existences of tamoxifen and its actual metabolites varies from 7 to 14 days. In long haul treatment, the convergences of tamoxifen and its metabolites in serum stay stable for whatever length of time that 10 years and its decreased bioavailability is not a reason for Blocking of estrogen receptors (Tamoxifen and Raloxifene). SERM: Selective estrogen receptor modulators procured resistance. Tamoxifen can recognize in serum for a few weeks and in cancerious tissue for a while after the action is ended. The counter tumor impacts of tamoxifen are thought to be because of its anti-estrogenic movement interceded by aggressive hindrance of estrogen tying to estrogen receptors. 

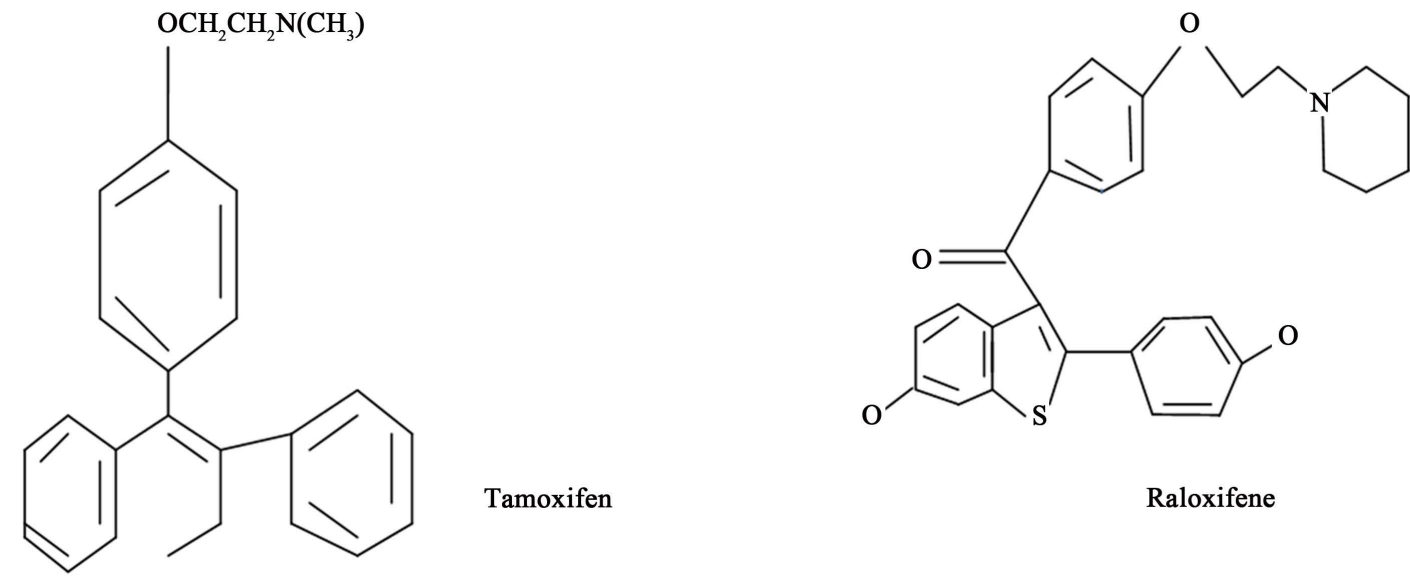

Tamoxifen

Raloxifene

Figure 2. Shows Tamoxifen and Raloxifene blocking. Selective estrogen receptor modulators.

As an outcome, tamoxifen represses the statement of estrogen-controlled qualities including growth factors and angiogenic components emitted by the tumor that may fortify the development via autocrine or paracrine techniques. The net outcome is obstructing the G1 period of the cell cycle and a regulating of cell reproduction. Tumors replace in view of this modified harmony between cell growth and constant cell misfortune. Tamoxifen straightforwardly affects customized cell demise in tumor tissues and it diminishes the danger of repeat and passing from breast malignancy furthermore it gives powerful vindication to patients with metastatic breast disease [2] [26]. Consequently it is helpful to treat the women who have estrogen-receptorpositive intrusive breast disease. A special case may be on the premise of prognostic components, for example, an intrusive or tube-like mucinous or papillary cancer with harmful axillary hubs-to have an okay of scattered malady. Tamoxifen is a beginning hormonal treatment of decision for postmenopausal women with metastatic breast growth and it is used as first-or second-line cure in young women. It is secure and very much endured; however the danger of endometrial growth is high.

\section{Raloxifene}

Raloxifene is a second era of specific estrogen-receptor modulators (SERM) and it was at first created for breast disease. Later, it was dealt with as a different option for hormone substitution treatment for cure of osteoporosis. Raloxifene is a benzothiophene lesser with a particularly distinctive structure from tamoxifen [25] [27]. In spite of the fact that, raloxifene has comparative action to tamoxifen in breast and bone it is without agonist act in the endometrium. Raloxifene is decreases the occurrence of breast tumor by $62 \%$, and it doesn't build the endometrial multiplication or neo-plasm [28] [29]. Raloxifene altogether lessens the danger of intrusive breast tumor in human with positive estrogen receptor status and diminishes the danger of clinical vertebral cracks (responsive decrease 35\%) yet it doesn't diminish the non-vertebral breaks. Be that as it may, it would lessen thromboembolism (44\%), fetal stroke (49\%), leg issues, fringe edema and gallbladder sickness in breast malignancy patients. The impact of raloxifene on breast tumor occurrence has been accounted for from a few progressing trials [27] [30]. The biggest randomized trial to address the issue of breast malignancy danger is with raloxifene action. In the Many Outcomes of Raloxifene Estimate (MORE) study, 7705 postmenopausal women with osteoporosis were randomized to get either raloxifene at 60 or $120 \mathrm{mg} / \mathrm{d}$ or fake action. Breast malignancy was checked in the MORE study and beginning reports demonstrated $70 \%$ decrease in the frequency of intrusive breast disease with raloxifene treatment contrasted and fake treatment. Raloxifene diminished the occurrence of estrogen receptor-positive breast malignancies and did not decrease the estrogen receptor-negative tumors. Raloxifene expands the BMD and it may bring down the crack danger in human. Raloxifene is not connected with endometrial expansion, yet clear data on raloxifene's impact on endometrial disease improvement is not yet available [31] [32].

\section{Estrogen Synthesis Inhibitors (Aromatase)}

Aromatase inhibitors are uniquely smothering the plasma estrogen levels in postmenopausal women by suppressing or deactivating aromatase, the compound in charge of union of estrogens from androgenic substrates. 
Aromatase is a protein of cytochrome P-450 family and the outcome of the CYP19 quality and it is existing at minor levels in a few nonglandular tissues containing subcutaneous fat, liver, muscle, cerebrum, ordinary breast, and breast malevolence tissue [29] [33]. Fringe aromatase action and plasma estrogen levels are linked with body-mass list in postmenopausal women. The convergence of estradiol in breast cancer tissue is around 10 times more than the fixation in plasma. The level of estrogen is high in breast tumor patient and estrogen sends a development sign to ER taking after which uncontrolled multiplication of cells happen. Aromatase inhibitors obstruct the estrogen flagging that prompts less development signs to ER and subsequently malignancy development can be backed off or ceased. Aromatase inhibitors delay a few cytochrome P-450 proteins involved in adrenal steroidogenesis and these are regenerated for use as "restorative adrenalectomy" in contradiction of cutting edge breast disease [34] [35]. They are shown as first , second and third-era inhibitors as showed by the sequential demand of their clinical advancement and they are more named sort 1 sort 2 inhibitors as per their element of activity. Sort 1 inhibitors are steroidal correspondents of androstenedione and they draw to the same site on the aromatase particle. Sort I inhibitors, not at all like androstenedione, tie irreversibly to aromatase and gets changed over to response intermediates. Along these lines, they are generally known as catalyst in activators. Sort 2 inhibitors are non-steroidal and link reversibly to the heme assembly of the catalyst through fundamental nitrogen particle. Anastrozole and letrozole are third-era inhibitors and they tie at their triazole bunches. Anastrozole, letrozole and exemestane are managed orally to the breast disease patients. Sort I compound and a sort II compound have clinical viability, yet the detriment of intramuscular infusions is required to convey the particles. Aminoglutethimide prompts cytochrome P-450 action, however it lessens tamoxifen levels. The third-era aromatase inhibitors must been detected in pre-clinical revisions to be more intense than aminoglutethimide [36]. Every one of them especially smothers the plasma estrogen levels in postmenopausal women. Clinical measurements of anastrozole, exemestane and letrozole are more noteworthy than 97 percent as contrasted and aminoglutethimide [32] [37]. Letrozole was connected with more prominent aromatase hindrance than anastrozole and reduced the plasma levels of estrogen and estrogen sulfate. Aromatase has intra tumoral movement in the dominant part of breast carcinomas and isotopic tests demonstrated that such action adds to diminish the plasma estrogen levels. Anastrozole, letrozole as well exemestane are mainly restraining breast growth. Universal trials confirmed that aromatase inhibitors good to tamoxifen in post -menopausal ER positive peoples, auxiliary to diminish repeat as well an abatement in unwanted reactions of endometrial malignancy and intravenous thrombosis. The problem with aromatase inhibitors is the higher degree of osteoporosis and resulting crack and in addition higher cholesterol levels [29].

\section{Estrogen Receptor down Regulators (Fulvestrant)}

Fulvestrant is the particular estrogen receptor down controller and FDA has as of late endorsed it for use in cutting edge breast disease and metastatic malignancy. The agonist features of tamoxifen as well different SERMs can add to an expanded danger of endometrial cancer and the improvement of fight in tumor cells. Fulvestrant is a 7-alkyl simple of estradiol having a special instrument of activity when contrasted and tamoxifen as well different SERMs. Tamoxifen ties to the ER outcomes in separation of warmth stun proteins, homodimerization as well hindrance of transactivation in breast cells. Fulvestrant actions distinctively tying to ER and reasons separation of warmth stun proteins. Be that as it may, the massive side chain of fulvestrant counteracts dimerization and results in corruption of ER. The outcome is hindrance of ER action as well as an emotional decrease in ER expression levels. As an aftereffect of down administrative action, fulvestrant has been termed a SERD Fulvestrant has prominent adequacy in tamoxifen refractory illness and it has shown an equal or unrivaled movement than anastrozole in the metastatic growths. There has been late verbal confrontation existing in the dosing of fulvestrant in people [38]. The distributed pharmacokinetic information recommended that, once in a month of intra solid infusion of fulvestrant at the dosage rate of $250 \mathrm{mg}$ gives a satisfactory measurement in the course, however it doesn't achieve the relentless state level rapidly. Further investigation of dosing of $250 \mathrm{mg}$ once in 2 weeks will achieve a consistent state more quickly in the dissemination. The fundamental unfriendly impacts of fulvestrant are sickness, vomition, blockage and the runs. Interestingly, fulvestrant does not fractious the bloodmind hindrance and it appears to bring about fewer menopausal side effects than different antiestrogens. It doesn't actuate endometrial thickening, however more catch up to the bigger clinical trials would be needed to survey its impacts on endometrial tumor danger [35] [39]. 


\begin{tabular}{|c|c|c|c|c|}
\hline Drug Name & Mechanism of action & $\begin{array}{l}\text { Chemical } \\
\text { formula }\end{array}$ & History & Applications \\
\hline Tamoxifen & $\begin{array}{l}\text { It is metabolized in the liver by the } \\
\text { cytochrome p450 isoform CYP2D6 } \\
\text { and CYP3A4 into active metabolites } \\
\text { such as 4-hydroxytamoxifen and } \\
\text { N-desmethyl-4-hydroxytamoxifen which } \\
\text { have } 30 \text { - } 100 \text { times more affinity with the } \\
\text { estrogen receptor than tamoxifen itself. }\end{array}$ & $\mathrm{C}_{26} \mathrm{H}_{29} \mathrm{NO}$ & $\begin{array}{l}\text { Discover in } 1967 \text { most } \\
\text { important drug need } \\
\text { for basic health system. }\end{array}$ & $\begin{array}{l}\text { Tamoxifen is currently } \\
\text { used for the treatment } \\
\text { of both early and } \\
\text { advanced ER+ } \\
\text { (estrogen receptor } \\
\text { positive) breast } \\
\text { cancer in pre- } \\
\text { and post-menopausal } \\
\text { women. }\end{array}$ \\
\hline Fulvestrant & $\begin{array}{l}\text { When fulvestrant binds to estrogen } \\
\text { receptor monomers it inhibits receptor } \\
\text { dimerization, activating function } 1 \text { (AF1) } \\
\text { and AF2 are rendered inactive, } \\
\text { translocation of receptor to the } \\
\text { nucleus is reduced, and degradation } \\
\text { of the estrogen receptor is accelerated. }\end{array}$ & $\mathrm{C}_{32} \mathrm{H}_{47} \mathrm{~F}_{5} \mathrm{O}_{3} \mathrm{~S}$ & $\begin{array}{c}\text { Fulvestrant is another } \\
\text { antiestrogen, and is the only } \\
\text { pure antiestrogen, or silent } \\
4 \text { KB (380 words)-16:12, } 21 \\
\text { January 2016 }\end{array}$ & $\begin{array}{l}\text { It is indicated for the } \\
\text { treatment of hormone } \\
\text { receptor positive } \\
\text { metastatic breast } \\
\text { cancer in } \\
\text { postmenopausal } \\
\text { women. }\end{array}$ \\
\hline $\begin{array}{l}\text { Aromatase } \\
\text { inhibitors }\end{array}$ & $\begin{array}{l}\text { Aromatase inhibitors work by inhibiting } \\
\text { the action of the enzyme aromatase, } \\
\text { which converts androgens into } \\
\text { estrogens by a process called aromatization. }\end{array}$ & C17-H11-N5 & $\begin{array}{l}\text { The commercial names } \\
\text { and year of approval in } \\
\text { the United States are: } \\
\text { letrozole (Femara, 1995). }\end{array}$ & $\begin{array}{l}\text { Used in the treatment } \\
\text { of breast cancer and } \\
\text { ovarian cancer in } \\
\text { postmenopa-usal } \\
\text { women and } \\
\text { gynecomastia in men. }\end{array}$ \\
\hline Raloxifene & $\begin{array}{l}\text { Enter the nucleus of the target organ } \\
\text { cells in order to bind there to a series } \\
\text { of unoccupied, inactive proteins, called ER. }\end{array}$ & $\mathrm{C}_{28} \mathrm{H}_{27} \mathrm{NO}_{4} \mathrm{~S}$ & $\begin{array}{c}\text { Tumor registry and } \\
\text { membership files identify } \\
\text { women diagnosed with } \\
\text { breast cancer after } 1994 \\
\text { who were health plan members } \\
\text { in } 1998 \text { or later, when } \\
\text { raloxifene became available }\end{array}$ & $\begin{array}{l}\text { Raloxifene is indicated } \\
\text { for the treatment and } \\
\text { prevention of } \\
\text { osteoporosis in } \\
\text { postmenopausal } \\
\text { women. }\end{array}$ \\
\hline
\end{tabular}

\section{Hydroxychloroquine (HCQ)}

HCQ can increment antiestrogen responsiveness in MCF7-RR and LCC9 cells and tumors, likely through the hindrance of autophagy. Be that as it may, the blend of ICIPHCQ was less viable than HCQ alone in vivo, not at all like the TAMPHCQ mix. Antiestrogen treatment fortified angiogenesis in tumors however did not counteract HCQ viability. The lower adequacy of ICIPHCQ was connected with ICI impacts on cell-interceded invulnerability inside of the tumor microenvironment. The mouse chemokine KC (CXCL1) and IFNg were differentially controlled by both TAM and ICI medicines, proposing a conceivable impact on macrophage advancement/action. Reliable with these perceptions, TAMbHCQ treatment expanded tumor CD68 cells invasion, while ICI and ICIPHCQ diminished fringe tumor macrophage content. Additionally, macrophage end of breast tumor target cells in vitro was lessened after introduction to ICI. HCQ restores antiestrogen affectability to safe tumors [40] [41].

\section{Antiestrogen-Resistant MCF7}

By consistent society of the estrogen-responsive parental line in steroid-drained, ICI 182,780 (Faslodex; 1027 M)-enhanced medium. Following a 90-day to development concealment, cells started to multiply in ICI 182,780 at degrees like those of unprocessed wild-sort cells. Immunocytochemistry demonstrated that such cells have decreased estrogen receptor as well a nonappearance of progesterone receptor proteins. RT-PCR as well as temporary transfection examines with estrogen reaction component journalist builds affirmed that ICI 182,780smothered estrogen reaction component interceded flagging. FASMCF cells express expanded reliance upon epidermal growth component receptor (EgfR)/mitogen-actuated protein kinase (MAPK)- interceded flagging [42]. Accordingly, EgfR protein but also dispatcher RNA, development reactions to changing development calculate an, and extracellular sign managed kinase 1/2 MAPK activationlevels are all expanded. Not at all like wild-sort cells, FASMCF cells are profoundly delicate to development restraint by an EgfR-particular tyrosinekinase blocking agents (TKI), ZD1839 (Iressa) as well as an blocking agent of the enactment of MEK1 (MAPKK), PD098059. Small-term (3 weeks) removal of cells from antiestrogen had no influence on growth or 
phenotype, though more removal (>10 weeks) seemed to mostly turn around the cell phenotype with expanding estrogen receptor also diminishing EgfR levels. FASMCF cells remained kept up in TKI, their development existed again smothered and optional TKI struggle neglected to create inside of the 90-day period in which starting ICI 182,780 struggle emerged. Besides, wild-sort cells also kept up in mix ICI 182,780 and TKI cure conditions persisted development captured ( $>180$ days), with remarkable cell misfortune from side to side both diminished rates of cell expansion and expanded cell demise [43] [44].

\section{GRP78, the Unfolded Protein Response and Breast Cancer}

GRP78, otherwise called BiP or HSPA5, is a protein chaperone included in controlling the endoplasmic reticulum stress pathway, the unraveled protein reaction (UPR) .Unraveled protein reaction, GRP78, was seen to be raised in endocrine-safe. overexpression of GRP78 in MCF7 and LCC1 antiestrogensensitive cells lines brought about medication resistance, while knockdown of GRP78 in MCF7-RR andLCC9 endocrine-safe breast tumor cells restored drug affectability, unmistakably exhibiting a vital part for GRP78 in influencing antiestrogen responsiveness [45]. Additionally, GRP78 overexpression in MCF7-BUS (estrogen-touchy) breast malignancy cells brought about the hindrance of estrogen starvation-affected apoptosis and mitochondria permeablization, proposing a part of GRP78 in AI resistance. While initially ensnared in UPR flagging, it was accounted for that GRP78 is discovered confined outside the endoplasmic reticulum and manages a few pathways including apoptosis, autophagy and digestion system, all of which may manage antiestrogen responsivenessbreast malignancy and specifically influenced antiestrogen treatment responsiveness [46].

\section{BCL2 and CASP8 Regulation with NF-_B}

Hindrance of NF-_B (p65/RELA), either by overexpression of a mutant I_B (I_BSR) or a little particle inhibitor of NF-_B (parthenolide; IC50_500 nM in tamoxifen-safe cells), synergistically restores affectability to 4-hydroxytamoxifen (4HT) in safe MCF7/RR what's more, MCF7/LCC9 cells and further sharpens MCF-7 and MCF7/LCC1 control cells to 4HT. These impacts are free of changes in either cell cycle dispersion or in the level of autophagy measured by hindrance of p62/SQSTM1 expression and cleavage of LC3. NF-_B restraint restores the capacity of 4HT to diminish BCL2 expression, increment mitochondrial layer penetrability, and prompt a CASPASE-subordinate apoptotic cell demise in safe cells. Each of these impacts is turned around by a CASPASE 8 (CASP8)-particular inhibitor that squares chemical substrate binding. Thus expanded enactment of NF-_B can modify affectability to tamoxifen by regulating CASP8 action, with ensuing consequences for BCL2 expression, mitochondrial capacity and apoptosis. Combination of parthenolide and tamoxifen may offer a novel helpful way to deal with the administration of some ER-positive breast tumors [47] [48].

\section{GX15-070 Antiestrogen-Resistant}

GX15-070 is more successful in decreasing the cell thickness of antiestrogen-safe breast growth cells versus touchy cells and this expanded affectability of safe cells to GX15-070 associates with a gathering of autophagic vacuoles. Development of autophagosomes in GX15-070-treated cells was confirmed by changes in articulation of the lipidation of microtubuleassociated protein-1 light chain-3 and both confocal and transmission electron microscopy. While GX15-070 treatment advances autophagic vacuole and autolysosome arrangement, p62/ SQSTM1, a marker for autophagic debasement, levels amass. Additionally, GX15-070 presentation prompts a diminishment in cathepsin D (CTSD) and L (CTSL1) protein expression that would somehow or another overview autolysosome payload. In this manner, GX15-070 has double parts in advancing cell passing: (i) straightforwardly hindering antiapoptotic BCL2 relatives, along these lines actuating apoptosis; and (ii) repressing downstream CTSD and CTSL1 protein expression to restrain the capacity of cells to utilize corrupted material to fuel cell digestion system and restore homeostasis [49] [50].

\section{BCL-W and BCL2 Co-Inhibition}

Coordinated parts of the antiapoptotic BCL-W and BCL2 in influencing responsiveness to the antiestrogen ICI 182,780 (ICI; Fulvestrant Faslodex), utilizing both sub-atomic (siRNA; shRNA) and pharmacologic (YC137) approaches in three breast malignancy variations; MCF-7/LCC1 (ICI delicate), MCF-7/LCC9 (ICI safe), and LY2 (ICI safe). YC137 restrains BCL-W and BCL2 and restores ICI affectability in safe cells. Co-hindrance of 
BCL-W and BCL2 is both essential and adequate to restore affectability to ICI, and clarifies robotically the activity of YC137. These information involve utilitarian collaboration and/or excess in motioning between BCL-W and BCL2, and recommend that expansive BCL2 family member inhibitors will have more noteworthy helpful worth than focusing on just individual proteins. Though ICI delicate MCF-7/LCC1 cells experience expanded apoptosis because of ICI taking after BCL-W6BCL2 co-hindrance, the ensuing resensitization of safe MCF-7/LCC9 and LY2 cells reflects increments in autophagy (LC3 cleavage; p62/SQSTM1 expression) and corruption however not apoptosis or cell cycle capture [51]. Along these lines, all over again delicate cells and resensitized safe cells bite the dust through distinctive instruments. Taking after BCL-W + BCL2 co-restraint, concealment of practical autophagy by 3-methyladenine or BECN1 shRNA lessens ICI-impelled putrefaction yet restores the capacity of safe cells to pass on through apoptosis. These information exhibit the versatility of cell destiny systems in breast disease cells in the setting of antiestrogen responsiveness. Rebuilding of ICI affectability in safe cells seems to happen through an increment in autophagy-related rot [52].

\section{XBP1 and Antiestrogen Responsiveness}

Antiestrogen treatment actuates the unraveled protein reaction (UPR) in estrogen receptor-positive (ER_) breast malignancy. X-box tying protein 1 (XBP1), which exists in the transcriptionally latent un-spliced structure [XBP1(U)] and the joined dynamic structure [XBP1(S)], is a key UPR part intervening antiestrogen resistance. Utilizing novel joined and non-splice able types of XBP1, XBP1(U) works past being a predominant negative of XBP1(S) [53]. Both isoforms manage NF-_B action by means of ER_; XBP1(S) is stronger in light of the fact that it additionally straightforwardly directs p65/RelA expression. Fundamental signaling activities of spliced and unspliced XBP1 in breast cancer, establish NF-B to be a mediator of these activities, and identify XBP1 and its splicing to be novel therapeutic targets [54].

\section{Adverse Effects of Drug}

Tamoxifen cause vaginal dryness, low libido, mood swings, nausea and hot flashes. Side effects cause by raloxifene include infection, flu-like symptoms and sinusitis. leg cramps is another side effect cause by raloxifene. Those women which have heart disease should not take aromatase inhibitor [55]. Common side effects cause by aromatase inhibitor are joint and muscles pain. This pain may be in hands wrists feet ankle or other parts of body. Common side effects cause by fulvestrant include injection site reactions (pain, swelling, redness) constipation, diarrhea, upset stomach, dizziness, headache, tiredness , cough, trouble sleeping, or trouble breathing. Side effects cause by hydroxylchloroquine blurred vision or any other change in vision [56].

\section{Conclusions}

Hostile to estrogen receptor methodologies incorporate obstructing by particular modulators (Tamoxifen and Raloxifene), destabilization and debasement of estrogen receptor by specific down controller (fulvestrant) and disturbance of estrogen combination (aromatase inhibitors, for example, anastrole, letrozole or exemestane), any of which alone can bring about a generous abatement of tumor development of estrogen receptor positive patients. Aromatase inhibitors ought to be utilized for hormonal treatment furthermore it is prevalent for counteractive action of recurrence. Use of expanded actuation of NF-_B can modify affectability to tamoxifen by adjusting CASP8 movement, with ensuing consequences for BCL2 expression, mitochondrial capacity, and apoptosis, which results in finding new atomic flagging influences antiestrogen responsiveness and unequivocally propose that a blend of parthenolide and tamoxifen may offer a novel remedial way to deal with the administration of some ER-positive breast cancer. The utilization of GX15-070 double parts in advancing cell passing: (i) straightforwardly restraining antiapoptotic BCL2 relatives, subsequently impelling apoptosis; and (ii) hindering downstream CTSD and CTSL1 protein expression to restrict the capacity of cells to utilize debased material to fuel cell digestion system and restore homeostasis, which could be utilized to outline novel restorative mediations for antiestrogen safe breast malignancy. BCL-W, BCL2, and BECN1 incorporate vital capacities in deciding antiestrogen responsiveness, and the vicinity of useful autophagy may impact the harmony in the middle of apoptosis and rot. Both isoforms of XBP1 manage NF-_B movement by means of ER_; XBP1(S) is more powerful in light of the fact that it likewise specifically controls p65/RelA expression. THIS discovering gives new experiences into the central flagging exercises of joined and un-spliced XBP1 in breast tumor, build up NF-_B 
to be an arbiter of these exercises, and distinguish XBP1 and its grafting to be novel remedial targets. HCQ another courses for restoring antiestrogen affectability to safe tumors. Additionally, the valuable combination of TAMPHCQ recommends a positive result for progressing neoadjuvant clinical trials utilizing this mix for the treatment of ERp ductal carcinoma in situ sores. Be that as it may, careful examination is required for all the connecting flagging pathways intervened through the estrogen receptor and development variable.

Review gives information about breast cancer, its sign and symptoms, risk factors, pathogenesis and diagnosis of breast cancer, drugs used against breast cancer and adverse effects of the drugs. By knowing all this information we build such a new drug which have no or low adverse effects and more effective against breast cancer as well as cost effective and minimize the risk of presently available drugs.

\section{References}

[1] Siegel, R., Naishadham, D. and Jemal, A. (2013) Cancer Statistics, 2013. CA: A Cancer Journal for Clinicians, 63, 11-30. http://dx.doi.org/10.3322/caac.21166

[2] Riggins, R.B., et al. (2005) Antiestrogens, Aromatase Inhibitors, and Apoptosis in Breast Cancer. Vitamins \& Hormones, 71, 201-237. http://dx.doi.org/10.1016/S0083-6729(05)71007-4

[3] Clarke, R., et al. (2001) Cellular and Molecular Pharmacology of Antiestrogen Action and Resistance. Pharmacological Reviews, 53, 25-72.

[4] Coultas, L. and Strasser, A. (2003) The Role of the Bcl-2 Protein Family in Cancer. Seminars in Cancer Biology, 13, 115-123. http://dx.doi.org/10.1016/s1044-579x(02)00129-3

[5] Youle, R.J. and Strasser, A. (2008) The BCL-2 Protein Family: Opposing Activities That Mediate Cell Death. Nature Reviews Molecular Cell Biology, 9, 47-59. http://dx.doi.org/10.1038/nrm2308

[6] Pattingre, S., et al. (2005) Bcl-2 Antiapoptotic Proteins Inhibit Beclin 1-Dependent Autophagy. Cell, 122, 927-939. http://dx.doi.org/10.1016/j.cell.2005.07.002

[7] Yang, Q., et al. (2003) Prognostic Value of Bcl-2 in Invasive Breast Cancer Receiving Chemotherapy and Endocrine Therapy. Oncology Reports, 10, 121-125. http://dx.doi.org/10.3892/or.10.1.121

[8] Cameron, D., et al. (2000) Effective Tamoxifen Therapy of Breast Cancer Involves Both Antiproliferative and Pro-Apoptotic Changes. European Journal of Cancer, 36, 845-851. http://dx.doi.org/10.1016/S0959-8049(00)00013-7

[9] Ellis, P., et al. (1998) Reduced Apoptosis and Proliferation and Increased Bcl-2 in Residual Breast Cancer Following Preoperative Chemotherapy. Breast Cancer Research and Treatment, 48, 107-116. http://dx.doi.org/10.1023/A:1005933815809

[10] Bachleitner-Hofmann, T., et al. (2002) Pattern of Hormone Receptor Status of Secondary Contralateral Breast Cancers in Patients Receiving Adjuvant Tamoxifen. Clinical Cancer Research, 8, 3427-3432.

[11] Campbell, R.A., et al. (2001) Phosphatidylinositol 3-Kinase/AKT-Mediated Activation of Estrogen Receptor $\alpha-A$ new Model for Anti-Estrogen Resistance. Journal of Biological Chemistry, 276, 9817-9824. http://dx.doi.org/10.1074/jbc.M010840200

[12] Nandi, S., Guzman, R.C. and Yang, J. (1995) Hormones and Mammary Carcinogenesis in Mice, Rats, and Humans: A Unifying Hypothesis. Proceedings of the National Academy of Sciences, 92, 3650-3657. http://dx.doi.org/10.1073/pnas.92.9.3650

[13] Clemons, M. and Goss, P. (2001) Estrogen and the Risk of Breast Cancer. The New England Journal of Medicine, 344, 276-285. http://dx.doi.org/10.1056/NEJM200101253440407

[14] Kumar, M.M., et al. (2007) A Mouse Model for Luminal Epithelial Like ER Positive Subtype of Human Breast Cancer. BMC Cancer, 7, 180. http://dx.doi.org/10.1186/1471-2407-7-180

[15] Jordan, V.C. (1995) "Studies on the Estrogen Receptor in Breast Cancer"-20 Years as a Target for the Treatment and Prevention of Cancer. Breast Cancer Research and Treatment, 36, 267-285. http://dx.doi.org/10.1007/BF00713399

[16] Merck Manual of Diagnosis and Therapy (2003) Breast Disorders: Breast Cancer. Retrieved 5 February 2008.

[17] Society, A.C. (2007) Breast Cancer Facts \& Figures 2007-2008. American Cancer Society Atlanta.

[18] Giordano, S.H., Cohen, D.S., Buzdar, A.U., Perkins, G. and Hortobagyi, G.N. (2004) Breast Carcinoma in Men. Cancer, 101, 51-57. http://dx.doi.org/10.1002/cncr.20312

[19] Nelson, H.D., Tyne, K., Naik, A., Bougatsos, C., Chan, B.K. and Humphrey, L. (2009) Screening for Breast Cancer: An Update for the US Preventive Services Task Force. Annals of Internal Medicine, 151, 727-737. http://dx.doi.org/10.7326/0003-4819-151-10-200911170-00009

[20] Lakhani, S.R. (1999) The Pathology of Familial Breast Cancer: Morphological Aspects. Breast Cancer Research, 1, 31-35. http://dx.doi.org/10.1186/bcr10 
[21] Saslow, D., et al. (2004) Clinical Breast Examination: Practical Recommendations for Optimizing Performance and Reporting. CA: A Cancer Journal for Clinicians, 54, 327-344. http://dx.doi.org/10.3322/canjclin.54.6.327

[22] Yu, Y.-H., Liang, C. and Yuan, X.-Z. (2010) Diagnostic Value of Vacuum-Assisted Breast Biopsy for Breast Carcinoma: A Meta-Analysis and Systematic Review. Breast Cancer Research and Treatment, 120, 469-479. http://dx.doi.org/10.1007/s10549-010-0750-1

[23] Fahey, S.L., et al. (1994) Clinical Pharmacology and Endocrinology of Long-Term Tamoxifen Therapy. The University of Wisconsin Press, Madison.

[24] Ellis, P.A., et al. (1997) Induction of Apoptosis by Tamoxifen and ICI 182780 in Primary Breast Cancer. International Journal of Cancer, 72, 608-613. http://dx.doi.org/10.1002/(SICI)1097-0215(19970807)72:4<608::AID-IJC10>3.0.CO;2-7

[25] Buzdar, A., Marcus, C., Holmes, F., Hug, V. and Hortobagyi, G. (1988) Phase II Evaluation of Lyl56758 in Metastatic Breast Cancer. Oncology, 45, 344-345. http://dx.doi.org/10.1159/000226637

[26] Cummings, S.R., et al. (1999) The Effect of Raloxifene on Risk of Breast Cancer in Postmenopausal Women: Results from the MORE Randomized Trial. JAMA, 281, 2189-2197. http://dx.doi.org/10.1001/jama.281.23.2189

[27] Fisher, B., et al., Other National Surgical Adjuvant Breast and Bowel Project Investigators (1998) Tamoxifen for Prevention of Breast Cancer: Report of the National Surgical Adjuvant Breast and Bowel Project P-1 Study. Journal of the National Cancer Institute, 90, 1371-1388. http://dx.doi.org/10.1093/jnci/90.18.1371

[28] Evans, C.T., Ledesma, D.B., Schulz, T.Z., Simpson, E.R. and Mendelson, C.R. (1986) Isolation and Characterization of a Complementary DNA Specific for Human Aromatase-System Cytochrome P-450 mRNA. Proceedings of the National Academy of Sciences of the United States of America, 83, 6387-6391. http://dx.doi.org/10.1073/pnas.83.17.6387

[29] Miller, W. and Dixon, J. (2001) Local Endocrine Effects of Aromatase Inhibitors within the Breast. The Journal of Steroid Biochemistry and Molecular Biology, 79, 93-102. http://dx.doi.org/10.1016/S0960-0760(01)00148-0

[30] Longcope, C., Baker, R. and Johnston, C. (1986) Androgen and Estrogen Metabolism: Relationship to Obesity. Metabolism, 35, 235-237. http://dx.doi.org/10.1016/0026-0495(86)90206-4

[31] Santen, R.J., Samojlik, E., Lipton, A., Harvey, H., Ruby, E.B., Wells, S.A. and Kendall, J. (1977) Kinetic, Hormonal and Clinical Studies with Aminoglutethimide in Breast Cancer. Cancer, 39, 2948-2958. http://dx.doi.org/10.1002/1097-0142(197706)39:6<2948::AID-CNCR2820390681>3.0.CO;2-9

[32] Steele, R.E., Mellor, L.B., Sawyer, W.K., Wasvary, J.M. and Browne, L.J. (1987) In Vitro and in Vivo Studies Demonstrating Potent and Selective Estrogen Inhibition with the Nonsteroidal Aromatase Inhibitor CGS 16949A. Steroids, 50, 147-161. http://dx.doi.org/10.1016/0039-128X(83)90068-5

[33] Howell, A. (2001) Preliminary Experience with Pure Antiestrogens. Cancer Research, 7, 4369s-4375s.

[34] Clarke, R., et al. (2003) Antiestrogen Resistance in Breast Cancer and the Role of Estrogen Receptor Signaling. Oncogene, 22, 7316-7339. http://dx.doi.org/10.1038/sj.onc.1206937

[35] Howell, A., Robertson, J.F.R., Albano, J.Q., Aschermannova, A., Mauriac, L., Kleeberg, U.R., Vergote, I., Erikstein, B., Webster, A. and Morris, C. (2002) Fulvestrant, Formerly ICI 182,780, Is as Effective as Anastrozole in Postmenopausal Women with Advanced Breast Cancer Progressing after Prior Endocrine Treatment. Journal of Clinical Oncology, 20, 3396-3403. http://dx.doi.org/10.1200/JCO.2002.10.057

[36] MacNeill, F., Jones, A.L., Jacobs, S., Lønning, P.E., Powles, T.J. and Dowsett, M. (1992) The Influence of Aminoglutethimide and Its Analogue Rogletimide on Peripheral Aromatisation in Breast Cancer. British Journal of Cancer, 66, 692-697. http://dx.doi.org/10.1038/bjc.1992.339

[37] Geisler, J., et al. (1998) In Vivo Inhibition of Aromatization by Exemestane, a Novel Irreversible Aromatase Inhibitor, in Postmenopausal Breast Cancer Patients. Clinical Cancer Research, 4, 2089-2093.

[38] Howell, A., DeFriend, D.J., Blamey, R.W., Robertson, J.F. and Walton, P. (1995) Response to a Specific Antioestrogen (ICI 182780) in Tamoxifen-Resistant Breast Cancer. The Lancet, 345, 29-30. http://dx.doi.org/10.1016/S0140-6736(95)91156-1

[39] Clarke, R., Dickson, R.B. and Lippman, M.E. (1992) Hormonal Aspects of Breast Cancer: Growth Factors, Drugs and Stromal Interactions. Critical Reviews in Oncology/Hematology, 12, 1-23. http://dx.doi.org/10.1016/1040-8428(92)90062-U

[40] Maycotte, P., Aryal, S., Cummings, C.T., Thorburn, J., Morgan, M.J. and Thorburn, A. (2012) Chloroquine Sensitizes Breast Cancer Cells to Chemotherapy Independent of Autophagy. Autophagy, 8, 200-212. http://dx.doi.org/10.4161/auto.8.2.18554

[41] Mukhopadhyay, A., Helgason, G.V., Karvela, M. and Holyoake, T.L. (2011) Hydroxychloroquine for Chronic Myeloid Leukemia: Complete Cure on the Horizon? Expert Review of Hematology, 4, 369-371. http://dx.doi.org/10.1586/ehm.11.34 
[42] Larsen, S.S., Egeblad, M., Jäättelä, M. and Lykkesfeldt, A.E. (1999) Acquired Antiestrogen Resistance in MCF-7 Human Breast Cancer Sublines Is Not Accomplished by Altered Expression of Receptors in the ErbB-Family. Breast Cancer Research and Treatment, 58, 41-56. http://dx.doi.org/10.1023/A:1006232830161

[43] Smith, L.M., Wise, S.C., Hendricks, D.T., Sabichi, A.L., Bos, T., Reddy, P., Brown, P.H. and Birrer, M.J. (1999) cJun Overexpression in MCF-7 Breast Cancer Cells Produces a Tumorigenic, Invasive and Hormone Resistant Phenotype. Oncogene, 18, 6063-6070. http://dx.doi.org/10.1038/sj.onc.1202989

[44] Kurokawa, H., et al. (2000) Inhibition of HER2/neu (erbB-2) and Mitogen-Activated Protein Kinases Enhances Tamoxifen Action against HER2-Overexpressing, Tamoxifen-Resistant Breast Cancer Cells. Cancer Research, 60, 58875894.

[45] Schwarze, S. and Rangnekar, V. (2010) Targeting Plasma Membrane GRP78 for Cancer Growth Inhibition. Cancer Biology \& Therapy, 9, 153-155. http://dx.doi.org/10.4161/cbt.9.2.10760

[46] Yahiro, K., Morinaga, N., Satoh, M., Matsuura, G., Tomonaga, T., Nomura, F., Moss, J. and Noda, M. (2006) Identification and Characterization of Receptors for Vacuolating Activity of Subtilase Cytotoxin. Molecular Microbiology, 62 , 480-490. http://dx.doi.org/10.1111/j.1365-2958.2006.05379.x

[47] Kim, H., Chung, H., Kim, H.-J., Lee, J.-Y., Oh, M.-Y., Kim, Y. and Kong, G. (2008) Id-1 Regulates Bcl-2 and Bax Expression through p53 and NF- $\kappa$ B in MCF-7 Breast Cancer Cells. Breast Cancer Research and Treatment, 112, $287-$ 296. http://dx.doi.org/10.1007/s10549-007-9871-6

[48] Kawauchi, K., Araki, K., Tobiume, K. and Tanaka, N. (2008) p53 Regulates Glucose Metabolism through an IKK-NF- $\kappa$ B Pathway and Inhibits Cell Transformation. Nature cell Biology, 10, 611-618. http://dx.doi.org/10.1038/ncb1724

[49] Tang, Y., Hamed, H.A., Cruickshanks, N., Fisher, P.B., Grant, S. and Dent, P. (2012) Obatoclax and Lapatinib Interact to Induce Toxic Autophagy through NOXA. Molecular Pharmacology, 81, 527-540. http://dx.doi.org/10.1124/mol.111.076851

[50] Thomssen, C., et al. (1995) Prognostic Value of the Cysteine Proteases Cathepsins B and Cathepsin L in human breast Cancer. Clinical Cancer Research, 1, 741-746.

[51] Gjertsen, B.T., Bredholt, T., Anensen, N. and Vintermyr, O.K. (2007) Bcl-2 Antisense in the Treatment of Human Malignancies: A Delusion in Targeted Therapy. Current Pharmaceutical Biotechnology, 8, 373-381. http://dx.doi.org/10.2174/138920107783018381

[52] Tavernarakis, N. and Samara, C. (2008) Autophagy and Cell Death in Caenorhabditis elegans. Current Pharmaceutical Design, 14, 97-115. http://dx.doi.org/10.2174/138161208783378770

[53] Cook, K.L., Shajahan, A.N., Wärri, A., Jin, L., Hilakivi-Clarke, L.A. and Clarke, R. (2012) Glucose-Regulated Protein 78 Controls Cross-Talk between Apoptosis and Autophagy to Determine Antiestrogen Responsiveness. Cancer Research, 72, 3337-3349. http://dx.doi.org/10.1158/0008-5472.CAN-12-0269

[54] Chen, X., et al. (2014) XBP1 Promotes Triple-Negative Breast Cancer by Controlling the HIF1 $\alpha$ Pathway. Nature, 508, 103-107. http://dx.doi.org/10.1038/nature13119

[55] Willhite, S.L., Goebel, S.R. and Scoggin, J.A. (1998) Raloxifene Provides an Alternative for Osteoporosis Prevention. The Annals of Pharmacotherapy, 32, 834-837. http://dx.doi.org/10.1345/aph.17335

[56] Flach, A.J. (2007) Improving the Risk-Benefit Relationship and Informed Consent for Patients Treated with Hydroxychloroquine. Transactions of the American Ophthalmological Society, 105, 191-197. 